\title{
Optimal Design of Cascaded Control Scheme for PV System Using BFO Algorithm
}

\author{
R.N.Kalaam ${ }^{1}$, Hany M. Hasanien ${ }^{2}$, Ahmed Al-Durra ${ }^{1}$, Khaled Al-Wahedi ${ }^{1}$, S. M. Muyeen ${ }^{1}$ \\ ${ }^{1}$ Electrical Engineering Department, The Petroleum Institute, P.O.Box 2533, Abu Dhabi, UAE. \\ ${ }^{2}$ Electrical Power \& Machines Department, Ain Shams University, Faculty of Engineering, Cairo, Egypt \\ e-mail:rankalaam@pi.ac.ae
}

\begin{abstract}
In this paper presents Bacteria Foraging Optimization (BFO) algorithm based approach to find the optimum design values for the Proportional-Integral (PI) Controllers in cascaded structure is presented. Tuning the values of four PI controllers is very complex when the system is difficult to express in terms of mathematical model due to system nonlinearity. Response surface methodology (RSM) is used to formulate a mathematical design which is required to apply optimization algorithm. To examine the performance of BFO algorithm in obtaining optimum values of multiple PI controllers, a grid connected Photovoltaic (PV) system is chosen. Transient performance of the PI controller with optimum design values is evaluated under grid fault conditions. The system is simulated using PSCAD/EMTDC. Simulation results have shown the validity of the optimal design values obtained from RSM-BFO approach under different disturbances and system parameter variations.
\end{abstract}

\section{INTRODUCTION}

Recently solar power generation systems are used to alleviate the problem of greenhouse emissions worldwide. Solar energy, being the most important renewable energy is considered to be the power source for future. As opposed to the prevailing sources like gasoline, coal, etc. solar energy is universally available, costless and inexhaustible. In 2013 renewables set a new record of more than 120 Gigawatts $(\mathrm{GW})$ despite of its high installation cost [1]. To make use of renewable energy sources, they need to be integrated with the existing power grid. For this purpose the power electronic converters are used. In the control strategy of the renewable energy systems including the power electronic converters, the cascaded topology of proportional-integral (PI) controllers are generally used.

The classical PI controller due to its robustness to disturbances and wide stability margin [2,3] has been used in many control applications. However choosing the optimal values of PI controller parameters is complex particularly for system with nonlinearities, high order and dynamic responses. Ziegler-Nichols method[4] is one of the used methods for tuning the PI controller parameters. But the accuracy of tuning depends on the design engineer experience. The artificial intelligence algorithms like fuzzy logic and neural network techniques have been proposed for tuning [5, 6]. In fuzzy logic, building the membership function is too hard. The neural network has the drawback of the convergence problem and time taken for training the sets.
In recent times, evolutionary computation techniques like Genetic Algorithm, Differential Evolution and Ant Colony Algorithm are gaining great research interests due to their potential to solve real world problems in various engineering domains. Their advantages are non-model based

approach and computational efficiency. They are conceptually simple with initialization of random sample. The traditional methods are more prone to changing dynamic conditions while evolutionary algorithms are more robust and adapt to the changing environment[7].

There are some applications like renewable energy systems which are purely non-linear. It is complex to formulate the mathematical equations to denote the system or a transfer function for the components of the whole system. In such cases the aforementioned algorithms can be used to get the optimal design values. Suitable parameters of controllers can greatly enhance the stability of system and attain ideal dynamic response characteristics. In this paper BFO Algorithm, the bio inspired algorithm based on the foraging nature of $E$-coli in the human intestine is proposed to optimize the design variables of the PI controller. This swarm based algorithm has the advantage regarding the global solution, randomness and direction of movement. A multi objective function is obtained from the response surface methodology and optimized using the BFO algorithm. The design variables obtained are simulated in PSCAD/EMTDC to validate the Algorithm. The paper is organized as follows.

In Section II, the PV system is represented briefly. Section III describes the optimal design using RSM and BFO algorithm. Section IV gives the detailed the optimization procedure. Section V presents the simulation results and discussion followed by the conclusion in Section VI.

\section{PV SYSTEM MODEL}

The PV application is selected to explain the usefulness of the optimal design of PI controllers operated in cascaded form. A $5 \mathrm{MW}$ (peak) PV plant which is grid connected is modeled and is shown in Fig. 1. It consists of PV panels with two power converters where cascaded controllers are being used. The PV unit also has a DC-DC boost converter to record the maximum power point (MPP), a three phase voltage source inverter (VSI) and a DC link capacitor are used to conserve a relatively constant DC voltage at the DC link and to transfer sinusoidal current to the grid. A LCL filter is used to interconnect an 
inverter to the utility grid which filters the harmonics generated by the inverter. PLL is used for synchronization between gridinterfaced converters and the grid. A delta-wye (wye grounded) transformer is employed to incorporate the system to the grid. For this modeling solar modules of Kyocera KC200GT [8] are used and the parameters are obtained from[9]. A DC distribution system is modeled based on [10] and parameters are referred from TOP SOLAR XZ-K (AS) $1 \times 300 \mathrm{~mm}^{2}$ cable [11]. A Double transmission line model is given due consideration in this paper.

\section{a) Chemotaxis}

This step is accomplished during the course of swimming and tumbling by flagella. Flagella rotation decides if bacteria need to progress in a predefined direction by swimming or in a diverse direction by tumbling. To denote a tumble, a unit length $\phi(j)$ in incidental direction is initiated. This defines the direction of velocity after a tumble. Each bacteria $\theta^{i}(j, k, l)$ modifies its new location by the equation given below

$$
\theta^{i}(j+1, k, l)=\theta^{i}(j, k, l)+\mathrm{C}(\mathrm{i}) \phi(\mathrm{i})
$$

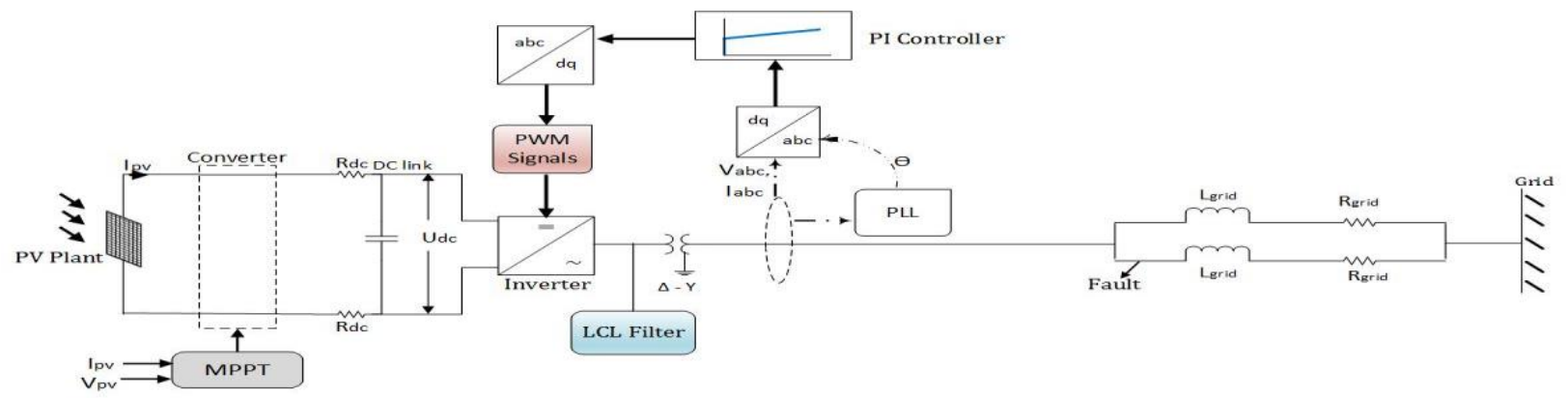

Fig. 1. Schematic structure of PV system

The PI controllers used in the system are optimized in this study. The inverter contains four PI controllers namely PI-1, PI-2, PI-3 and PI-4 as shown in the Fig.2. Table IV in the Appendix lists the system model parameters and line parameter values.

\section{OPTIMAL DESIGN}

\section{A. The RSM}

The Response Surface Methodology (RSM) is a statistical method which has the capability modeling, pondering, and optimizing the design in engineering field. The RSM consists of techniques used in the development of an adequate functional relationship between a response and design variables through the statistical fitting method. The RSM facilitates objective functions to be created with less computing burden. In this study, PSCAD software is used for numerical simulations to yield the response graph. The recovery time after fault $\left(\mathrm{T}_{\mathrm{r}}\right)$ is considered as the response which is changed by the design variables variant. The secondorder model of the RSM is used in this study for attaining a good and stable response. The formation of the response surface is based on the central composite design (CCD) which helps to give a fitted second order polynomial $[12,13]$

\section{B. Bacteria Foraging Optimization (BFO) Algorithm}

BFO Algorithm is a class of biologically motivated global search practice which follows the searching nature of E.coli bacteria. It was originally introduced by Passino in 2002[14] and it does not need accurate mathematical models. Since it is an emerging algorithm, BFO has been used in number of applications. The algorithm contains four steps: Chemotaxis, Swarming, Reproduction, and Elimination and Dispersal. where $\theta^{\iota}(j, k, l)$ denotes the $\mathrm{i}^{\text {th }}$ bacteria at $\mathrm{j}^{\text {th }}$ chemotactic, $\mathrm{k}^{\text {th }}$ reproductive, and $\mathrm{l}^{\text {th }}$ elimination and dispersal step. $\mathrm{C}(\mathrm{i})$ is the size of the step in random direction specified by the length unit.

\section{b) Swarming}

In swarming step any bacteria which finds optimal location with food sends the information to other bacteria in the group by releasing a cell-cell attractant. They assemble together to form a group with high bacterial concentration and move in a homocentric pattern in order to reach the proper destination with high density. This process can be denoted mathematically as

$$
J_{c c}\left(\theta, P(j, k, l)=\sum_{i=1}^{S} J_{c c}^{i}\left(\theta, \theta^{j}(j, k, l)\right.\right.
$$

where $J_{c c}(\theta, P(j, k, l)$ is the cost function value to be added to the actual cost function to be minimized to present a timevarying cost function. $S$ is the total count of bacteria and $P$ is the total count of design variables to be optimized.

\section{c) Reproduction}

In reproduction step the fittest bacteria with best health rupture into two bacteria and the bacteria with worst health dies. Thus the population remains constant.

d) Elimination and dispersal

The final step in the process is the Elimination and dispersal. With the intention of avoiding local optimum solution, an elimination-dispersal event takes place where some bacteria are killed or dispersed into a new environment. The dispersed bacteria may also assist in next chemotaxis process if the new environment has higher gradient of nutrients.

This paper mainly emphasize on using this emerging practice to optimize the design variables of the PI controller. The detailed theoretical background and derivations are found in literature $[14,15]$. The objective of this study is to reduce 
the recovery time after fault $(Y)$. For this purpose code is written on Matlab and iterations are performed.

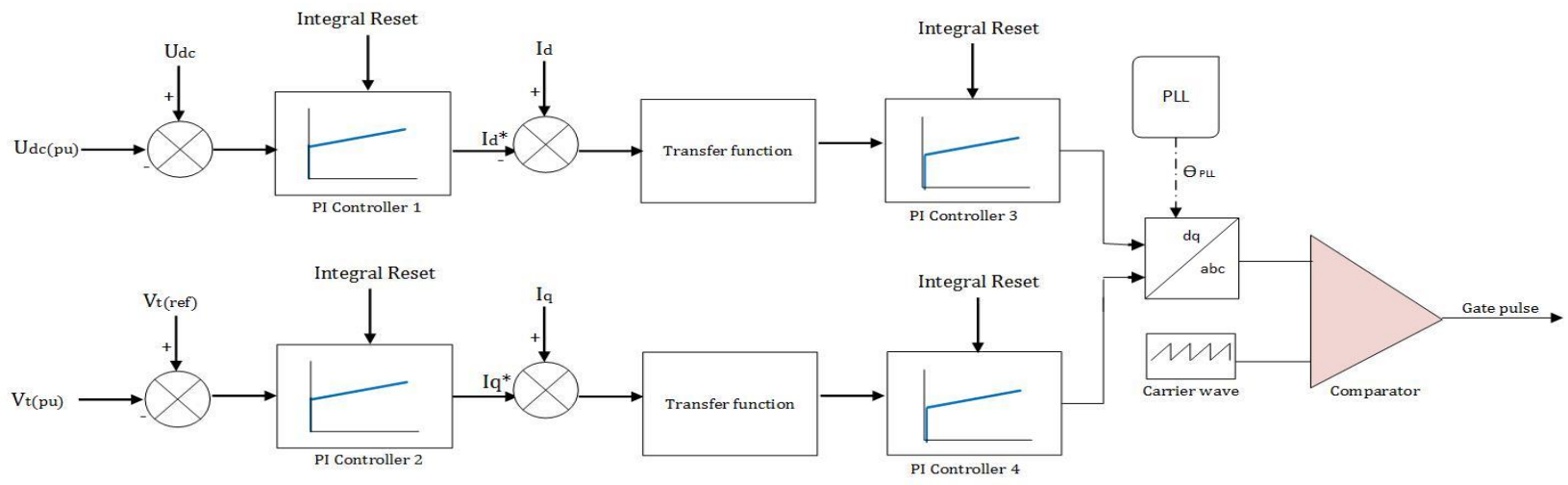

Fig. 2. PI Controllers in Inverter

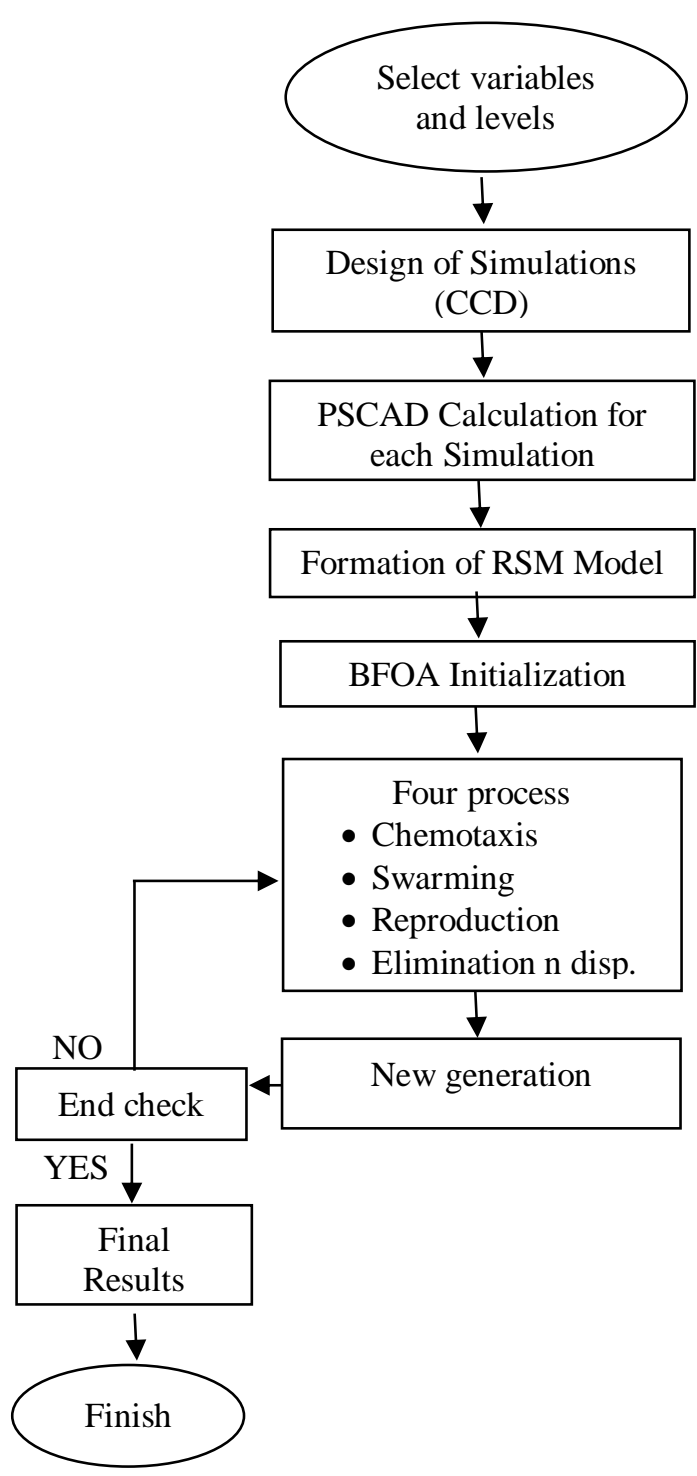

Step 1) Select Variables and Levels:

In this study, the proportional gain and integral time constant of the PI controllers are chosen to be the design variables. $X_{1}$ is the proportional gain of PI-1 and PI-2, $X_{2}$ is the integral time constant of PI-1 and PI-2(for simplicity the design variables PI-1 and PI-2 are assumed to be the same), $X_{3}$ is the proportional gain of PI-3, and is the $X_{4}$ integral time constant of PI-3. $X_{5}$ is the proportional gain of PI-4, $X_{6}$ is the integral time constant of PI- $4, X_{7}$ is the proportional gain of PI-5, and is the $X_{8}$ integral time constant of PI-5. These variables are assigned three levels to denote a range of values. Level 1, level 2 and level 3 represents minimum (-1), average (0) and maximum (1) values respectively as shown in Table I

Table I DESIGN VARIABLES AND LEVELS

\begin{tabular}{|c|c|c|c|c|c|c|c|c|}
\hline $\begin{array}{l}\text { Design } \\
\text { variable } \\
\mathrm{s}\end{array}$ & $\mathrm{X}_{1}$ & $\mathrm{X}_{2}$ & $\mathrm{X}_{3}$ & $\mathrm{X}_{4}$ & $\mathrm{X}_{5}$ & $\mathrm{X}_{6}$ & $\mathrm{X}_{7}$ & $\mathrm{X}_{8}$ \\
\hline $1(-1)$ & 2 & 0.2 & $\begin{array}{c}0.00 \\
4\end{array}$ & 0.11 & 0.2 & 0.01 & 1 & 0.2 \\
\hline $2(0)$ & 7 & 1.2 & $\begin{array}{c}0.01 \\
7\end{array}$ & 0.55 & 0.8 & $\begin{array}{c}0.10 \\
5\end{array}$ & 4.5 & 0.85 \\
\hline $3(1)$ & 12 & 2.2 & 0.03 & 1 & 1.4 & 0.2 & 8 & 1.5 \\
\hline
\end{tabular}

Step 2) Design of Simulations:

The RSM approach is based on the central composite design for designing the responses. In this simulation, the experiment count of the CCD algorithm is set to 90[16].Few examples for the range and values is shown in the table II. This statistical design of simulation is formulated using the Minitab statistical software

Step 3) PSCAD Program Calculation:

Simulations are executed for every experiment and the time taken for recovery after fault is taken. 
Table II SAMPLE RANGE OF DESIGN VARIABLES AND EXPERIMENT FREQUENCY

\begin{tabular}{|c|c|c|c|c|c|c|c|c|c|}
\hline Exp. & $\mathrm{X}_{1}$ & $\mathrm{X}_{2}$ & $\mathrm{X}_{3}$ & $\mathrm{X}_{4}$ & $\mathrm{X}_{5}$ & $\mathrm{X}_{6}$ & $\mathrm{X}_{7}$ & $\mathrm{X}_{8}$ & $\mathrm{~T}_{\mathrm{r}}(\mathrm{s})$ \\
\hline 1 & -1 & -1 & -1 & -1 & -1 & -1 & 1 & 1 & 0.1986 \\
\hline 2 & 1 & -1 & -1 & -1 & -1 & -1 & -1 & -1 & 0.2054 \\
\hline 3 & -1 & 1 & -1 & -1 & -1 & -1 & -1 & -1 & 0.2047 \\
\hline 4 & 1 & 1 & -1 & -1 & -1 & -1 & 1 & 1 & 0.2049 \\
\hline 5 & -1 & -1 & 1 & -1 & -1 & -1 & -1 & 1 & 0.2003 \\
\hline 6 & 1 & -1 & 1 & -1 & -1 & -1 & 1 & -1 & 0.199 \\
\hline
\end{tabular}

Step 4) RSM Model

The fitted RSM model is created in this step for the response of recovery time $\left(T_{r}\right)$ and the focus of this study is to reduce $T_{r}$. The fitted second order polynomial is

$Y=0.18560-0.00506 \mathrm{x}_{1}-0.00373 \mathrm{x}_{2}+0.00178 \mathrm{x}_{3}$ $-0.00584 \mathrm{x}_{4} \quad-0.00051 \mathrm{x}_{5}+0.00077 \mathrm{x}_{6}+0.00427 \mathrm{x}_{7}-0.00499 \mathrm{x}_{8}$ $+0.01213 \mathrm{x}_{1} * \mathrm{x}_{1}+0.00918 \mathrm{x}_{2} * \mathrm{x}_{2}-0.00527 \mathrm{x}_{3} * \mathrm{x}_{3}+0.00233 \mathrm{x}_{4} * \mathrm{x}_{4-}$ $0.00532 \mathrm{x}_{5} * \mathrm{x}_{5}+0.00818 \mathrm{x}_{6} * \mathrm{x}_{6}-0.00917 \mathrm{x}_{7} * \mathrm{x}_{7}$

$-0.00567 \mathrm{x}_{8} * \mathrm{x}_{8}+0.00352 \mathrm{x}_{1} * \mathrm{x}_{2}$ $-0.00124 \mathrm{x}_{1} * \mathrm{x}_{3}$

$+0.00027 \mathrm{x}_{1} * \mathrm{x}_{4} \quad-0.00123 \mathrm{x}_{1} * \mathrm{x}_{5} \quad-0.00397 \mathrm{x}_{1} * \mathrm{x}_{6} \quad-$ $0.00219 \mathrm{x}_{1} * \mathrm{x}_{7}+0.00293 \mathrm{x}_{1} * \mathrm{x}_{8} \quad-0.00101 \mathrm{x}_{2} * \mathrm{x}_{3}$ $-0.00005 \mathrm{x}_{2} * \mathrm{x}_{4}+0.00326 \mathrm{x}_{2} * \mathrm{x}_{5}+0.00049 \mathrm{x}_{2} * \mathrm{x}_{6}-0.00212 \mathrm{x}_{2} * \mathrm{x}_{7}$ $+0.00325 \mathrm{x}_{2} * \mathrm{x}_{8} \quad+0.00280 \mathrm{x}_{3} * \mathrm{x}_{4}-0.00139 \mathrm{x}_{3} * \mathrm{x}_{5}$

$+0.00021 \mathrm{x}_{3} * \mathrm{x}_{6}$ $0.00029 \mathrm{x}_{3} * \mathrm{x}_{7}$ $0.00131 \mathrm{x}_{3} * \mathrm{x}_{8}+0.00109 \mathrm{x}_{4} * \mathrm{x}_{5}+0.00308 \mathrm{x}_{4} * \mathrm{x}_{6}-0.00027 \mathrm{x}_{4} * \mathrm{x}_{7}$ $+0.00100 \mathrm{x}_{4} * \mathrm{x}_{8}-0.00204 \mathrm{x}_{5} * \mathrm{x}_{6} \quad+0.00342 \mathrm{x}_{5} * \mathrm{x}_{7}$ $-0.00151 \mathrm{x}_{5} * \mathrm{x}_{8} \quad+0.00229 \mathrm{x}_{6}{ }^{*} \mathrm{x}_{7} \quad-0.00343 \mathrm{x}_{6} * \mathrm{x}_{8}$

$-0.00331 \mathrm{x}_{7} * \mathrm{x}_{8}$

Step 5) BFO Algorithm Optimization:

Now BFO Algorithm can be applied to this fitness function, $Y$ using MATLAB. The BFO Algorithm characteristics are shown in Table $\mathrm{V}$ in Appendix.

\section{SIMULATION RESULTS}

In this section the effectiveness of the BFO Algorithm for PI controller parameter optimization used in PV system is demonstrated. The BFO Algorithm was coded in MATLAB and iterations are performed. After the iteration completes the optimized values are obtained as listed in Table III. It can be seen that the values obtained were within the range specified in Table I.

Table III OPTIMAL LEVEL AND SIZE OF DESIGN VARIABLES

\begin{tabular}{|l|c|c|c|c|c|c|c|c|}
\hline $\begin{array}{l}\text { Variable } \\
\mathrm{s}\end{array}$ & $\mathrm{X}_{1}$ & $\mathrm{X}_{2}$ & $\mathrm{X}_{3}$ & $\mathrm{X}_{4}$ & $\mathrm{X}_{5}$ & $\mathrm{X}_{6}$ & $\mathrm{X}_{7}$ & $\mathrm{X}_{8}$ \\
\hline $\begin{array}{l}\text { Optimiz } \\
\text { ed } \\
\text { value }\end{array}$ & $\begin{array}{c}6.54 \\
45\end{array}$ & $\begin{array}{c}0.76 \\
86\end{array}$ & $\begin{array}{c}0.00 \\
46\end{array}$ & $\begin{array}{c}0.97 \\
92\end{array}$ & 1.4 & $\begin{array}{c}0.12 \\
84\end{array}$ & $\begin{array}{c}1.04 \\
52\end{array}$ & 1.5 \\
\hline
\end{tabular}

A symmetrical 3LG (three-line-to-ground) is considered at Fault location as shown in Fig. 1 in one of the double circuit transmission line and simulations are performed using PSCAD/EMTDC [17]. This network fault is considered as a network disturbance. The values obtained are checked if they are robust and rigid to disturbances. The simulation time is considered as $10 \mathrm{~s}$. The system is studied under standard test condition (STC) $\left(1000 \mathrm{~W} / \mathrm{m}^{2}\right.$ and $\left.25^{\circ} \mathrm{C}\right)$.

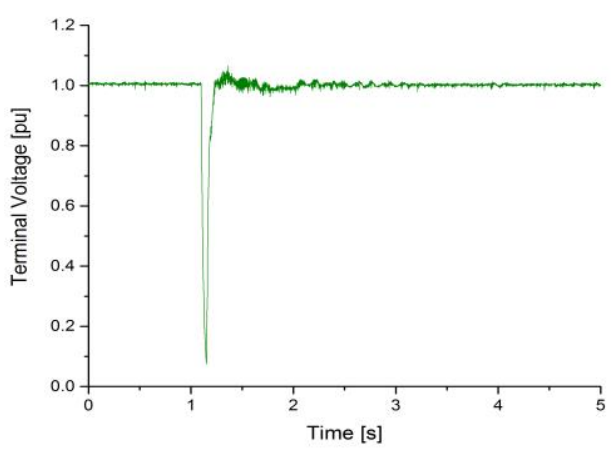

Fig.4. Grid side voltage (3LG fault) devoid of optimal value

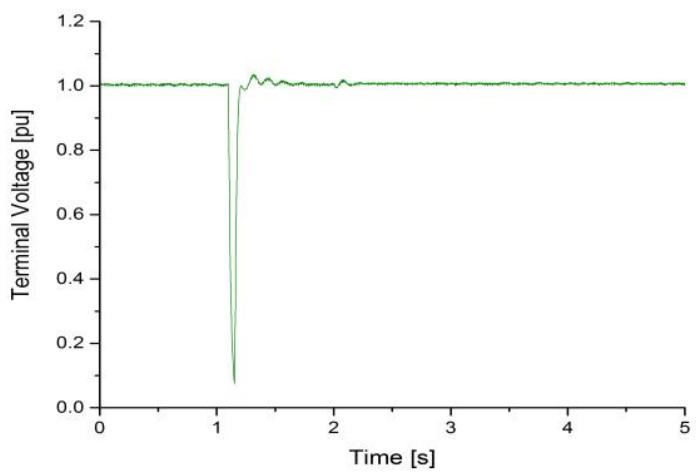

Fig.5. Grid side voltage (3LG fault) with optimizal value

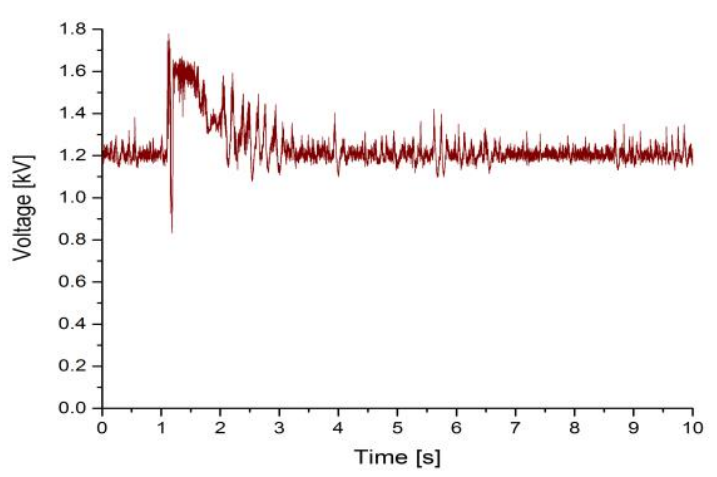

Fig.6. Voltage of DC link (3LG fault) devoid of optimal value

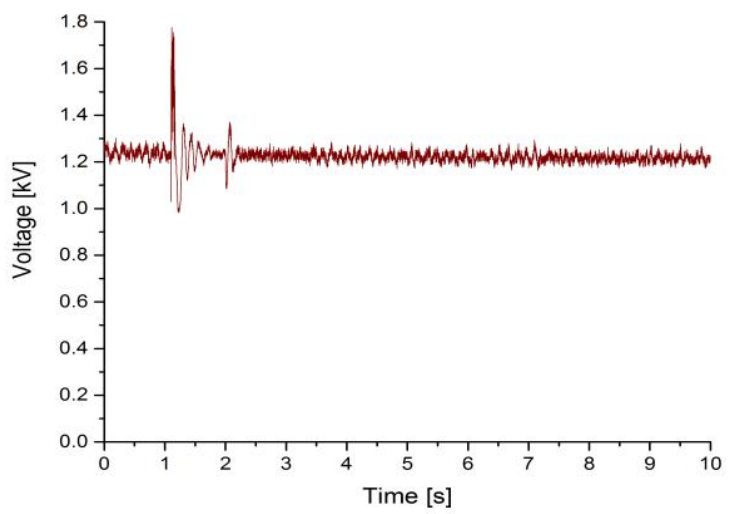

Fig.7. Voltage of DC link (3LG fault) with optimal value 


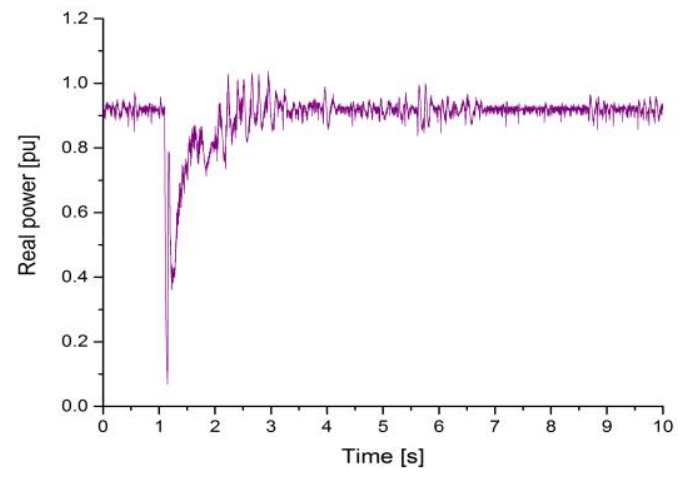

Fig.8. Grid side real power devoid of optimal value

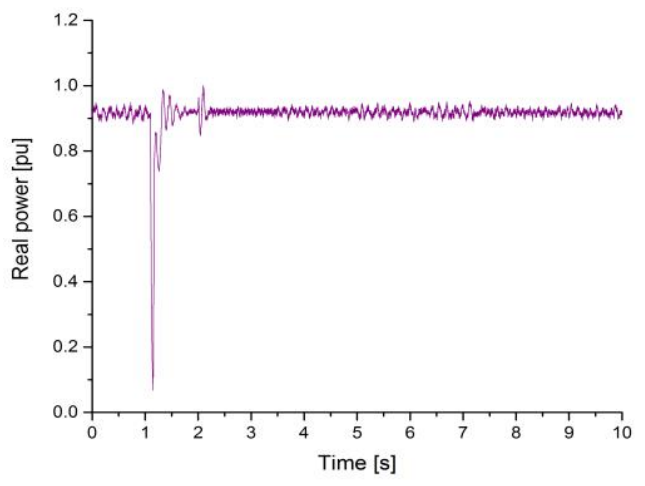

Fig.9. Grid side real power with optimal value

The Fig. 4 shows the terminal voltage when PI controllers are assigned some random values based on designer experience. It can be observed the recovery time is more than $0.2 \mathrm{sec}$ and the voltage is not smooth. When the optimized values are used, the recovery time after the fault is reduced to less than $2 \mathrm{sec}$ and also the voltage is smooth without the disturbance when the fault has occurred as shown by Fig. 5. The difference in DC link voltage can also be observed well. In Fig. 6 the voltage has overshoots high settling time with lot of spikes. When the optimized values are used the overshoot is reduced considerably with less settling time as depicted by Fig. 7 . The optimized value has its effect on the real power as shown by Fig. 8 and 9. The real power supplied also has less fluctuations when the values are optimized. From Fig. 8 it is evident that the real power also suffers from oscillations and it is fixed to an extent by the optimized value as shown in Fig. 9 .

\section{CONCLUSION}

In this paper, the detailed procedure for optimization using Bacteria Foraging algorithm to obtain the design variables of the multiple PI controllers in a cascaded structure is presented. The optimized values are used in 4 PI controllers to control the grid side inverter of the PV system. Three phase symmetrical grid fault is considered a network disturbance. It is found that the design values obtained from proposed RSM-BFO approach were finely tuned, improves the system performance to a satisfactory level and minimizes the recovery time which eventually helps the system to meet the grid code. Therefore it is concluded that BFO algorithm is very effective to tune PI controllers parameters in grid-connected PV system and can also be applicable to other renewable applications to get optimum values.

\section{APPENDIX}

Table IV PARAMETERS FOR 5 MW PV PLANT

\begin{tabular}{|l|l|}
\hline Peak power & $5 \mathrm{MW}$ \\
\hline Voltage at MPP & $973 \mathrm{~V}$ \\
\hline $\mathrm{N}_{\mathrm{S}}$ & 108 \\
\hline $\mathrm{N}_{\mathrm{M}}$ & 37 \\
\hline $\mathrm{N}_{\mathrm{P}}$ & 676 \\
\hline $\mathrm{R}_{\text {Seq }}$ & $0.0242 \Omega$ \\
\hline $\mathrm{R}_{\mathrm{Peq}}$ & $45.47 \Omega$ \\
\hline $\mathrm{a}$ & 1.3 \\
\hline
\end{tabular}

- $\quad \mathrm{N}_{\mathrm{S}}$ - The No. of series connected cells

- $\quad \mathrm{N}_{\mathrm{P}}$ - The No. of parallel connected cells

- $\quad N_{M}$ - The No. of series connected modules in a string

- $\quad a$-the ideality factor

- $R_{S}$ - equivalent series resistance

- $R_{P}$ - equivalent parallel resistances

- $\mathrm{R}_{\mathrm{Seq}}=\left(\mathrm{N}_{\mathrm{M}} \times \mathrm{R}_{\mathrm{S}}\right) / \mathrm{N}_{\mathrm{P}}$

- $\mathrm{R}_{\mathrm{Peq}}=\left(\mathrm{N}_{\mathrm{M}} \times \mathrm{R}_{\mathrm{P}}\right) / \mathrm{N}_{\mathrm{P}}$.

Table V LINE PARAMETERS

\begin{tabular}{|l|l|}
\hline Length of DC lines & $1 \mathrm{~km}$ \\
\hline $\mathrm{R}_{\mathrm{DC}}$ & $4.82 \times 10^{-4} \mathrm{ohm}$ \\
\hline $\mathrm{V}_{0}$ & $1.2 \mathrm{kV}$ \\
\hline $\begin{array}{l}\text { Transformer } \\
\text { voltage ratio }(\Delta-\mathrm{Y})\end{array}$ & $0.763 \mathrm{kV} / 22 \mathrm{KV}$ \\
\hline $\mathrm{R}_{\text {grid }}($ for each line) & $9.68 \Omega$ \\
\hline $\mathrm{L}_{\text {grid }}$ (for each line) & $0.18487 \mathrm{H}$ \\
\hline
\end{tabular}

Table VI BFO ALGORITHM CHARACTERISTICS

\begin{tabular}{|c|c|}
\hline $\mathbf{N}_{\mathbf{C}}$ & 50 \\
\hline $\mathbf{N}_{\mathbf{S}}$ & 8 \\
\hline $\mathbf{N}_{\mathbf{r e}}$ & 4 \\
\hline $\mathbf{N}_{\mathbf{e d}}$ & 2 \\
\hline $\mathbf{S}$ & 26 \\
\hline
\end{tabular}

- $\quad \mathrm{N}_{\mathrm{C}}$ - The No. of Chemotactic steps

- $\mathrm{N}_{\mathrm{S}}$ - Unit length of the swim

- $\mathrm{N}_{\mathrm{re}}$ - The No. of reproduction steps

- $\mathrm{N}_{\mathrm{ed}}$-The No. of elimination dispersal events

- $\mathrm{S}$ - Total count of bacteria 


\section{REFERENCES}

[1] Renewable power generation costs in 2014, online: http://www.irena.org.

[2] Åström, K.J. and T. Hägglund, The future of PID control. Control Engineering Practice, 2001. 9(11): p. 1163-1175.

[3] Yun, L., A. Kiam Heong, and G.C.Y. Chong, PID control system analysis and design. Control Systems, IEEE, 2006. 26(1): p. 32-41.

[4] Popadic, B., et al. Tuning methods for PI controller - Comparison on a highly modular drive. in Energy (IYCE), 2013 4th International Youth Conference on. 2013.

[5] Rubaai, A., M.J. Castro-Sitiriche, and A.R. Ofoli, Design and Implementation of Parallel Fuzzy PID Controller for High-Performance Brushless Motor Drives: An Integrated Environment for Rapid Control Prototyping. Industry Applications, IEEE Transactions on, 2008. 44(4): p. 1090-1098.

[6] Chengyi, G., S. Qing, and C. Wenjian, A Neural Network Assisted Cascade Control System for Air Handling Unit. Industrial Electronics, IEEE Transactions on, 2007. 54(1): p. 620-628.

[7] Jian-Ping, L., L. Xiao-Dong, and A. Wood. Species based evolutionary algorithms for multimodal optimization: A brief review. in Evolutionary Computation (CEC), 2010 IEEE Congress on. 2010.

[8] Kyocera KC200GT- high efficiency multicrystal photovoltaic module datasheet. Available from: http://www.kyocera.com.sg/products/solar/pdf/kc200gt.pdf.

[9] Villalva, M.G., J.R. Gazoli, and E.R. Filho, Comprehensive Approach to Modeling and Simulation of Photovoltaic Arrays. Power Electronics, IEEE Transactions on, 2009. 24(5): p. 1198-1208.

[10] M. R. Starke, a.L.T., DC Distribution with Fuel Cells as Distributed Energy Resources 2009.

[11] Cables for photovoltaic solar installations.; Available from: www.elesis.gr/php/download.php?file=solar_cables_presentation.pdf.

[12] Hasanien, H.M., Particle Swarm Design Optimization of Transverse Flux Linear Motor for Weight Reduction and Improvement of Thrust Force. Industrial Electronics, IEEE Transactions on, 2011. 58(9): p. 4048-4056.

[13] Ambia, M.N., et al., Harmony Search Algorithm-Based Controller Parameters Optimization for a Distributed-Generation System. Power Delivery, IEEE Transactions on, 2015. 30(1): p. 246-255.

[14] Passino, K.M., Biomimicry of bacterial foraging for distributed optimization and control. Control Systems, IEEE, 2002. 22(3): p. 52-67.

[15] Mishra, S., A hybrid least square-fuzzy bacterial foraging strategy for harmonic estimation. Evolutionary Computation, IEEE Transactions on, 2005. 9(1): p. 61-73.

[16] Mathews, P., Design of Experiments With MINITAB. American Society of Quality, Quality press, 2005.

[17] “PSCAD/EMTDC user's guide," Manitoba HVDC Research Center, 2005 